\title{
Analyzing the Association between ENSO and Groundwater Rise in the South Atlantic-Gulf Region in the Southeastern United States
}

\author{
Neekita Joshi ${ }^{1}$ and Ajay Kalra ${ }^{2, *(D)}$ \\ 1 Water Resources Division, Gewalt Hamilton Associates Inc., Vernon Hills, IL 60061, USA; \\ neekita.joshi@siu.edu \\ 2 School of Civil, Environmental and Infrastructure Engineering, Southern Illinois University, \\ Carbondale, IL 62901, USA \\ * Correspondence: kalraa@siu.edu; Tel.: +1-(618)-453-7008
}

Citation: Joshi, N.; Kalra, A. Analyzing the Association between ENSO and Groundwater Rise in the South Atlantic-Gulf Region in the Southeastern United States. Hydrology 2021, 8, 119. https://doi.org/ 10.3390/hydrology8030119

Academic Editors: Marco Delle Rose and Brindha Karthikeyan

Received: 12 June 2021

Accepted: 8 August 2021

Published: 11 August 2021

Publisher's Note: MDPI stays neutral with regard to jurisdictional claims in published maps and institutional affiliations.

Copyright: (C) 2021 by the authors. Licensee MDPI, Basel, Switzerland. This article is an open access article distributed under the terms and conditions of the Creative Commons Attribution (CC BY) license (https:/ / creativecommons.org/licenses/by/ $4.0 /)$.

\begin{abstract}
The primary goal of this study is to comprehend the effects of El Niño Southern Oscillation (ENSO) climate pattern on groundwater storage (GWS) in the South Atlantic-Gulf Region. Groundwater issues are complex and different studies focused on groundwater depletion while few emphasized "groundwater rise". The current research is designed to develop an outline for assessing how climate patterns can affect groundwater fluctuation, which might lead to groundwater rise. The study assessed the effect of ENSO phases on spatiotemporal variability of groundwater using Spearman Rank Correlation. A significant positive correlation between ENSO and GWS was observed. An increasing trend was detected in GWS where most grids were observed in Florida by utilizing the non-parametric Mann-Kendall test. A positive trend magnitude was also detected by utilizing Theil-Sen's Slope method with a high magnitude in the mid-Florida region. The highest GWS anomalies were observed in the peak of El Niño events and the lowermost GWS was observed during La Niña events. Furthermore, most of the stations were above normal groundwater conditions. This study provides a better insight on the research gap among groundwater rise and ENSO.
\end{abstract}

Keywords: GRACE; groundwater rise; ENSO; correlation analysis; climate variability

\section{Introduction}

Water resources planning and management is a fundamental step to ensure equitable and sustainable use of available surface and groundwater resources. The progressive development of the water resources is possible by limiting the available resources to external forces like population growth, climate change, land-use change, and extreme events which have a cumulative impact on the hydrological cycle. The hydrologic process governs the functioning of the overall ecosystem which is being altered by modifying the biophysical structures that obstruct the water cycle. Groundwater is one of the key components of the hydrologic cycle and plays a vital role in balancing the ecosystem. The effects in the hydrological cycle due to climate variability and change are significant [1].

Groundwater is a dynamic and complex system, and its sustainability is the main challenge as it is an extensive resource even without considering climate variability and change. The relationship and the effects of climate variability and change are challenging [2] as it is also influenced by anthropogenic activities [3]. To impact groundwater resources, a longterm climate change signal has to 'travel' through the following water cycle components: (a) precipitation, (b) streamflow, (c) soil moisture content, (d) interception and terrestrial water storage (TWS), and (e) evapotranspiration. The strength of the climate change signal as it passes through the aforementioned hydrologic components to affect the groundwater resource have not yet been thoroughly investigated.

In past decades, hydrologists and water managers had deeper insights into different modes of oceanic-atmospheric teleconnections occurring at different temporal and spatial 
scales. These modes occur at interannual and interdecadal time scales and provide predictive information about hydrologic variability (precipitation, streamflow, and groundwater) in regions around the world. Short-term hydrologic responses are due to seasonal climatic variability whereas complex interaction of interannual climate variability controls groundwater recharge and water table [4-9]. Some of the major modes of oceanic-atmospheric climate variability include the El Niño Southern Oscillation (ENSO), Pacific Decadal Oscillation, Atlantic Multi-decadal Oscillation, and North Atlantic Oscillation. ENSO is the most common mode of oceanic-atmospheric teleconnections that causes warming or cooling of the equatorial Pacific Ocean and has three phases: El Niño, La Niña, and neutral. These phases lead to variations in climatic settings in the central Pacific Ocean. El Niño describes the warm phase whereas La Niña represents the cool phase of Sea Surface Temperature (SST) around the world. Nevertheless, for a deeper knowledge on the effects on groundwater storage (GWS) and recharge due to ENSO, further research is required [10]. The information related to the groundwater fluctuation due to ENSO is important for informed decision-making as well as to understand the groundwater availability due to different phases of climate variability.

ENSO can have a significant influence on water-table rise or fluctuations [11-14]. The fluctuations in groundwater level are a natural phenomenon; however excessive rise leads to disruption of underground water infrastructures. In Saudi Arabia Jeddah Watershed, Al-Sefry, and Sen [15] mentioned that from 1996 to 2000 there was an average of $0.41 \mathrm{~m}$ of groundwater table rise. However, it is challenging to study the effects of ENSO on groundwater due to the absence of relevant long-term data [1]. A study in central India by Rishma and Katpatal [16] determined that the groundwater trend in the command area and non-command area showed an increasing trend. During ENSO warm events less groundwater storage was observed whereas during La Niña year high groundwater storage was observed within their study area. In addition, GWS trends were calculated by using Gravity Recovery and Climate Experiment (GRACE) estimates in India where increased recharge was observed during intense rainfall [17]. GRACE is an effective tool to quantify hydrologic processes, where spatial and temporal in situ groundwater data are limited [18]. Thomas and Famiglietti [19] mentioned that in Lower Missouri Basin increased GW storage estimated from GRACE was identified and corroborates positive trends in the upper Midwest and northeastern US. Furthermore, the northern High Plain Aquifer, northern California, and southern Nevada were found to have an increasing groundwater trend, whereas a decline in southern High Plain aquifer was also observed [20,21]. Thomas and Famiglietti [19] and Sahoo et al. [20] did not consider ENSO in their study while Russo and Lall [21] considered ENSO in their study.

The current study focused on assessing the association between groundwater rise and ENSO in the southeastern United States. It explored the changes in GWS estimated from GRACE satellites including groundwater recharge and precipitation. Furthermore, this study focused on "groundwater rise" whilst more focus is given to groundwater depletion. Therefore, this study will be an addition to the literature. To sufficiently relate the groundwater changes to ENSO, the current study analyzes the essential factors like variation of groundwater from the long-term mean (anomaly), monthly change estimation of groundwater, and recharge over time. These analyses mainly evaluate if the stations are whether above normal groundwater level (positive anomalies) or below normal groundwater level (negative anomalies). The study will address the following key questions: (1) What is the historic spatiotemporal variation in GWS? (2) Does groundwater have a significant relationship with ENSO? (3) Is groundwater level rising or falling? The specific objectives of this study are (1) analyzing the correlation between groundwater and ENSO climatic teleconnection using non-parametric Spearman rank correlation; (2) temporal trend analysis of groundwater storage; and (3) analyzing groundwater rise based on groundwater storage anomaly-negative anomaly indicate lower monthly groundwater level (GWL) and positive indicates higher than normal GWL. 
In addition, the scope of this study is to assess the spatiotemporal relationship between ENSO and variability in groundwater. The land-use practices could be a reason that could have a potential impact on the groundwater level, but the anthropogenic effect is not covered in the current study. In addition, factors affecting the groundwater levels include proximity to streams, lakes, and oceans, pumping, extraction, irrigation, drilling, drinking water, and groundwater well construction. These factors have not been included in the current study. Water-logging and soil salinity issues might also induce or amplify groundwater rise, however, it might not exists over all the states in the study region.

\section{Materials and Methods}

\subsection{Study Area}

The current study is carried out in the Southeast region of the United States. This lies in the Hydrologic Unit Code (HUC)-03 watershed inside the geographic boundaries of $22^{\circ}$ $\mathrm{N}$ to $36^{\circ} \mathrm{N}$ latitude and $71^{\circ} \mathrm{W}$ to $93^{\circ} \mathrm{W}$ longitude as shown in Figure 1 . The study area covers seven states such as Georgia, Mississippi, Alabama, Virginia, South Carolina, and North Carolina. This study area experiences a humid climate, and it generally has mild and occasional winter cold. During warm days, the weather is sunny and during spring it has cool mornings and evenings. The average rainfall ranges from 940 to $1420 \mathrm{~mm}$ each year and the high temperature usually ranges between $26^{\circ} \mathrm{C}$ and $32{ }^{\circ} \mathrm{C}$. Due to its proximity to the Ocean, thunderstorms and humid climates are common. The population density is 388 people per square $\mathrm{km}$ with the highest population in Florida having an estimated population of 21 million people.

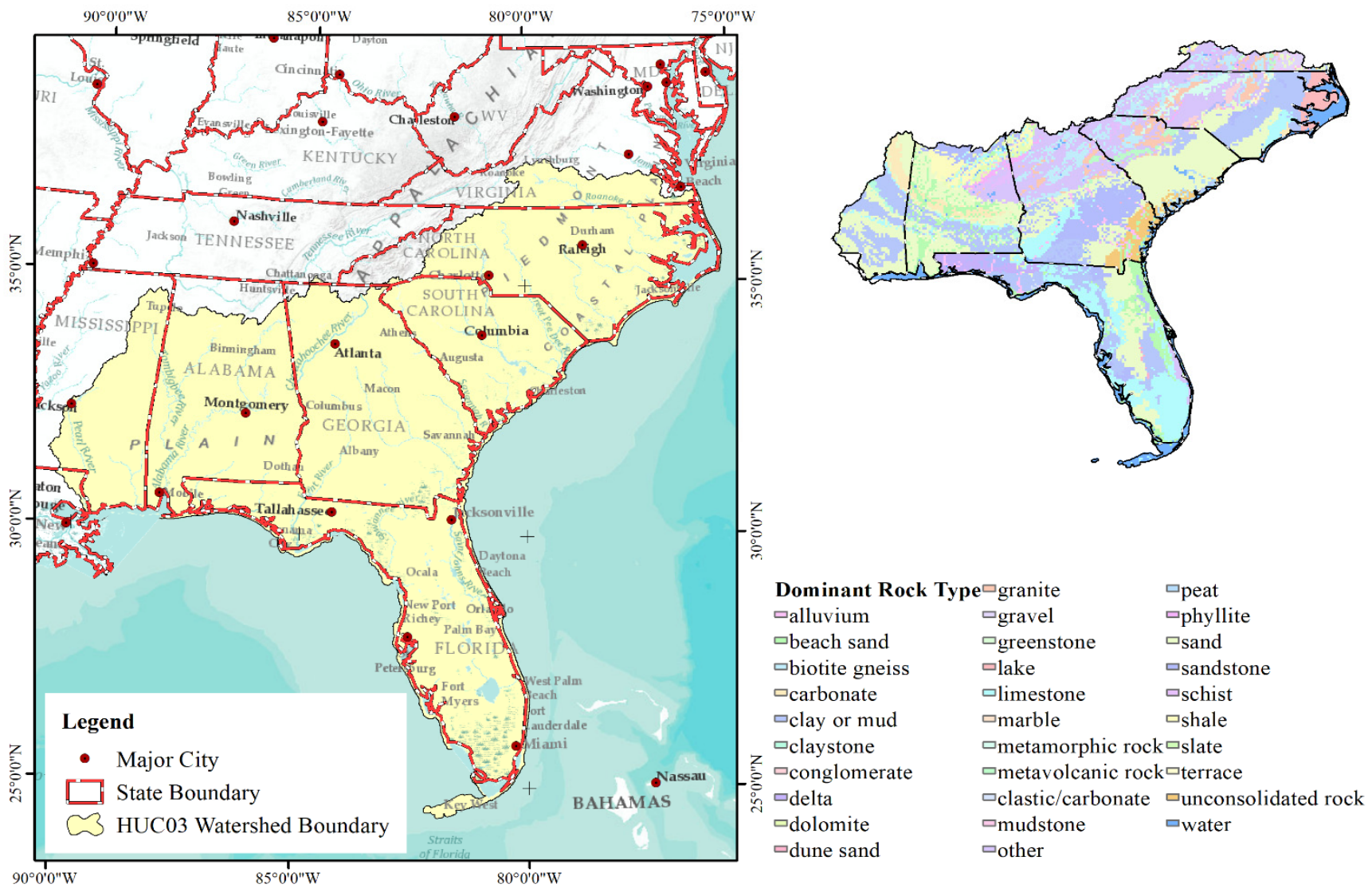

Figure 1. Location of main cities in HUC-03 watershed boundary and dominant rock-type.

The majority of the study region lies in the Floridian aquifer system (FAS). It spans Southeast Alabama, Georgia, South Carolina, and Florida. It is divided into upper and lower FAS and consists of limestone and dolomite. FAS consist of four major aquifers, 
namely, Sand and gravel, Biscayne, Surficial, and Intermediate aquifer system. The first aquifer contains of clay and sand with embedded layers of clay and silt, where confined conditions are formed by clay layers. The aquifer comprises two high permeability zones divided by less permeable sands and clays in Florida. A highly permeable limestone and less permeable sand and sandstone lie in the Biscayne aquifer. The highly permeable rocks of the Biscayne aquifer are enclosed by a thin layer of porous soil in most areas and the groundwater levels rise quickly in response to intense precipitation. The surficial aquifer system is unconfined and is composed of mainly unconsolidated shell, sand, and shelly sand. A confined layers in the intermediate aquifer system is formed by permeable layers of limestone, sand, and shell. Water penetrates downwards to the intermediate aquifer system in most parts of the study area. A schematic of a hydrogeological section is illustrated below in Figure 2.

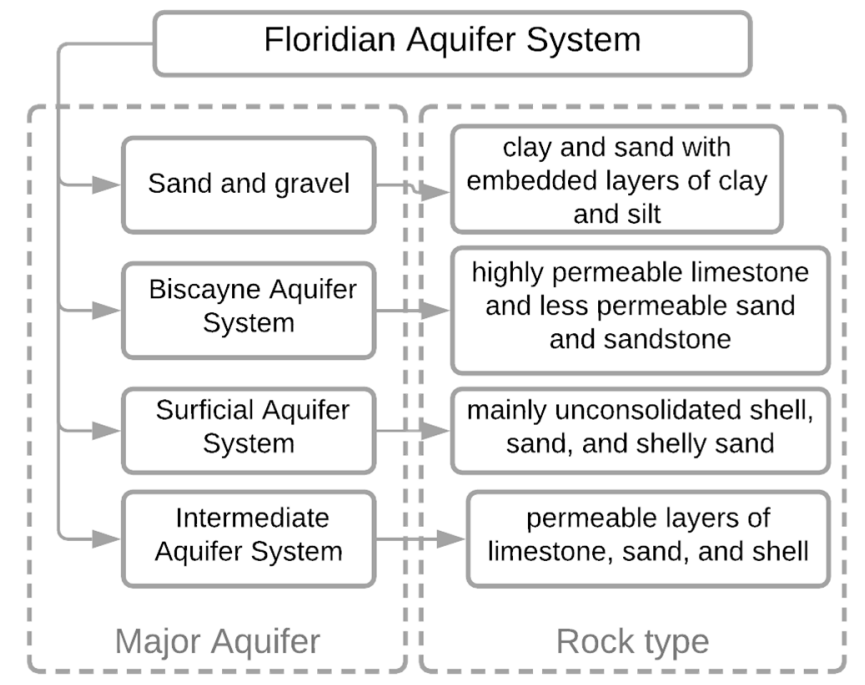

Figure 2. A schematic of a hydrogeological section of the study area.

\subsection{Datasets}

The current research used new mascon GRACE-RL06 CSR mascon solutions from 2002 to 2019 to evaluate the terrestrial water storage anomalies (TWSA), with a spatial resolution of $0.5^{\circ} \times 0.5^{\circ}$ derived from JPL to estimate the groundwater storage [22]. For the missing data, a linear interpolation approach was used to populate the time series based on the adjacent time series [23]. It is a comparatively simple interpolation technique from which a linear equation can be obtained, and a missing value can be computed. This approach is widely used, easy, and effectively handles missing data. The Soil Moisture (SM), Snow Water Equivalent (SWE), and Canopy Water Storage (CWS) variations over the study period were obtained from two land surface models (LSMs) - Noah (NOAH) and the Variable Infiltration Capacity (VIC) driven by the Global Land Data Assimilation System (GLDAS). The GLDAS data simulation system utilizes advanced LSMs and data integration methods by incorporating ground data acquisition and satellite data [24] and has high accuracy [25]. It has a good spatial resolution and is reliable with latest GRACE RL06 CSR mascon solutions. Thus, the current study used NOAH and VIC-LSM models for Groundwater Storage Anomaly (GWSA) calculation. The TWSA was calculated by multiplying JPL and scale factors. The required anomalies of soil moisture (SMA), snow water equivalent (SWEA), canopy water storage (CWSA), and terrestrial water storage (TWSA) were computed to estimate groundwater storage anomaly (GWSA) within the study area. The soil moisture was averaged for four depths from two LSM models, VIC, and NOAH. The anomalies from GRACE and GLDAS estimates used the baseline from 2004 through 2009. Both are monthly datasets measured in millimeters. A detailed description 
of GWSA estimation from GLDAS and GRACE is available in Joshi et al. [26]. The GWSA is calculated as in Equation (1) below:

$$
\text { GWSA }=\text { TWSA }-(\text { SMA }+ \text { SWEA }+ \text { CWSA }) .
$$

Direct gridded groundwater recharge datasets are not available in this study area, so the available baseflow data from the LSM model was used to provide ancillary data of groundwater recharge. The groundwater recharge was estimated by using the drainage from the bottom of the lowest soil layer simulated by the LSMs-VIC and NOAH. It is named "baseflow" in LSMs and used as suggested by Li et al. [27]. The time series of 247 well data was acquired from the National Groundwater Monitoring Network. The groundwater well data with less than $10 \%$ missing values were only considered. To be consistent with the station numbers and available data, a record length of 2002-2017 was considered to determine groundwater rise or fall. The monthly gridded precipitation data $(5 \times 5 \mathrm{~km})$ from Gridded $5 \mathrm{~km}$ GHCN-Daily Temperature and Precipitation Dataset (nClimGrid) was also used. The anomaly of precipitation data (PPTA) was also calculated to be consistent with GRACE by using a baseline from 2004 to 2009. The monthly ENSO index was obtained from an online database of NOAA [28]. The Niño-3.4 index was used that represents the El Niño phase (SST $>+0.5^{\circ} \mathrm{C}$ ), La Niña phase $\left(\mathrm{SST}<-0.5^{\circ} \mathrm{C}\right.$ ) and neutral phase the represents SST between $-0.5^{\circ} \mathrm{C}$ and $>+0.5^{\circ} \mathrm{C}$.

\subsection{Methods}

\subsubsection{Spearman Rank Correlation Analysis}

In this study, the first objective is to assess the ENSO influence on GWSA, and precipitation. Spearman Rank Correlation was computed in this study in order to investigate their linkage. It is a non-parametric method that helps in determining the relationship between the variables. It uses the rank of the records to calculate the correlation coefficient [29]. It does not assume Gaussian distribution, and thus it was used understand the teleconnection patterns. It is insensitive to extreme values (outliers), and the data need not be regularly spaced. It can be used for small sample sizes but while converting the data into ranks, information can be lost, and it can be less powerful than Pearson correlation analysis if the data is normally distributed. In this method, each variable is ranked in ascending order and the difference between ranks for each observed data is recorded. If the dataset is correlated, then the sum of squares of the difference between the ranks is small, and the magnitude is related to the significance of the correlation. The Spearman rank correlation coefficient is calculated by using Equation (2):

$$
R_{\rho}=1-\frac{\sum d_{i}^{2}}{n\left(n^{2}-1\right)},
$$

where, $R_{\rho}$ is Spearman's rank correlation coefficient, $d_{i}$ is the difference between the two ranks of each observed data, $\mathrm{n}$ is the number of observed data. The correlation coefficient value ranges from -1 for negatively correlated variables and 1 for positively correlated variables. The correlation coefficient is 0 if there is no connection between the variables. The correlation values greater than 0.5 denotes strong positive correlation and less than -0.5 denotes strong negative correlation. To test the significance of a correlation, we assumed that there is no correlation between ENSO and precipitation (or GWSA) at a 95\% confidence level $(p<0.05)$.

\subsubsection{Mann-Kendall Test and Theil-Sen Slope}

The second objective is to evaluate the trend of the groundwater levels from the available time series. Similar to the Spearman Rank, the Mann-Kendall test is also a non-parametric approach and was used to evaluate the trend in groundwater data. It is also insensitive to outliers and can be used in a small dataset. This approach was used to analyze the statistical significance of the trend in each grid of the GRACE dataset. The 
current study considered the trend at 10\% statistical significance. The Thiel-Sen approach (TSA) $[30,31]$ was used to estimate the magnitude of a trend. It is useful with discontinuous time series and is also insensitive to outliers. GWL is measured at irregular intervals varying from day-to-day to yearly values. To sufficiently assess the relationship between hydrological changes due to ENSO, the current study analyzed also analyzed the essential parameters like deviation of GWS by calculating groundwater anomaly within the study area. The average of GWSA and PPT was used for temporal analysis with the ENSO events within the study region.

\subsubsection{Determination of Groundwater Rise/Fall}

To attain the third objective of assessing the groundwater level rise or fall, depth to GWL anomaly was also generated and then a percentile suggested by USGS groundwater watch [32] was used to understand the water level conditions in terms of three categories, i.e., above normal, below normal and normal conditions as shown in Table 1. These groundwater level anomalies were then compared to groundwater rise or fall within the study area. Temporal maps of the number of stations under three categories were obtained to examine the groundwater conditions in the HUC-03 region.

Table 1. Groundwater level categorization to determine rise/fall.

\begin{tabular}{cc}
\hline Percentile & Groundwater Level Classes \\
\hline$<25$ & Below Normal \\
$25-75$ & Normal \\
$>75$ & Above Normal \\
\hline
\end{tabular}

\section{Results and Discussion}

\subsection{Historical Variations in Groundwater}

The long-term temporal trend presented in Figure 3 shows that the GWSA has increased from 2002 to 2019 within the study region. From the trend analysis between GWSA and ENSO in Figure 3i, it can be noted that the peak of ENSO events is consistent with the peak of the GWSA. The red-colored areas represent the El Niño event whereas the blue-colored areas represent the La Niña event. From the figure, a strong El Niño event is occurring during positive GWSA and the strong La Niña event is appearing during negative GWSA. When there is a peak La Niña event, an increase in the GWSA was observed. From the results, throughout the time of peak GWSA, peak El Niño events were observed. Similarly, in Figure 3ii, high precipitation during El Niño and less precipitation during the La Niña event were observed. The blue bars represent precipitation, and the red line represents recharge. The pattern of precipitation is also similar with ENSO and GWSA whereas the peak recharge is also during the peak precipitation events. ENSO mainly affects rainfall in Southeast US [33-35] which could help in explaining high-level GWSA during El Niño and less groundwater level during La Niña events. In the past, Florida had incidences of groundwater flooding due to heavy rainfall in various counties [36]. High, intense precipitation or above-normal precipitation could be one of the reasons that the groundwater level rose, and another reason could be the effect of ENSO. 
(i)

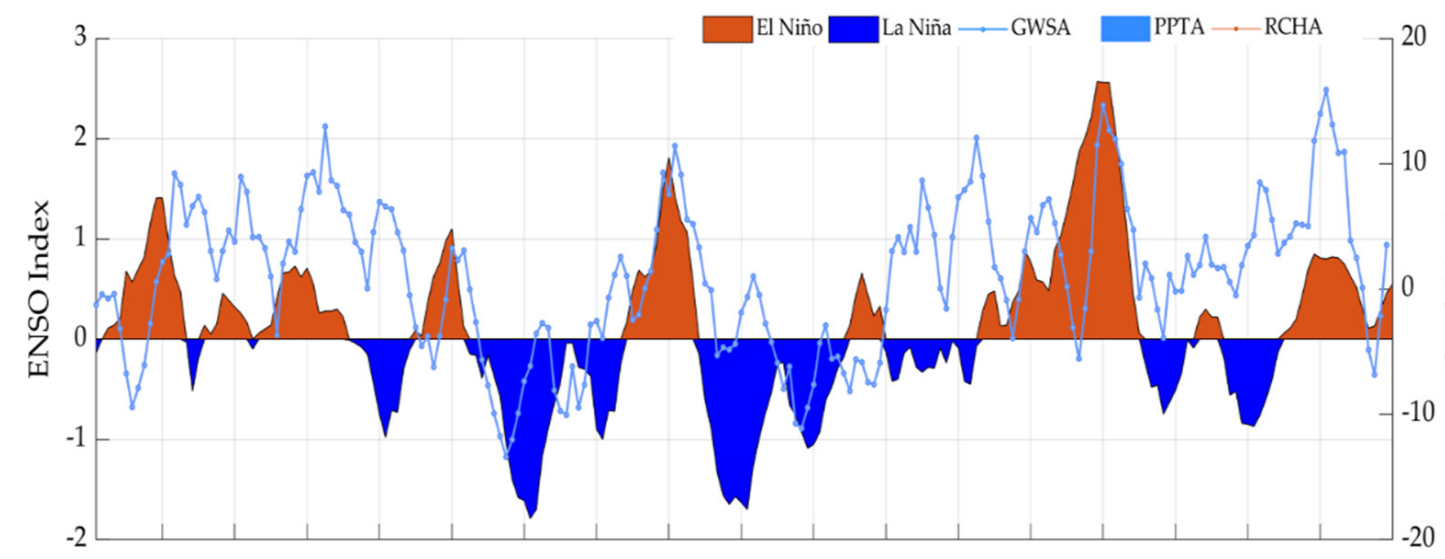

(ii)

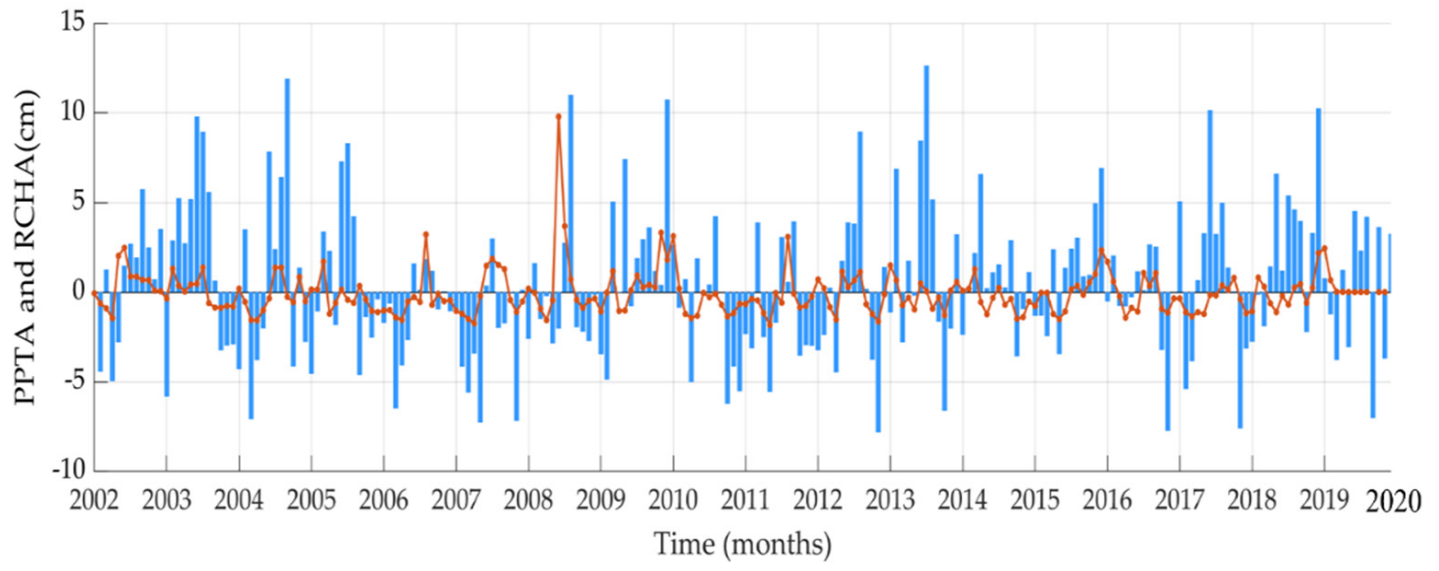

(iii)

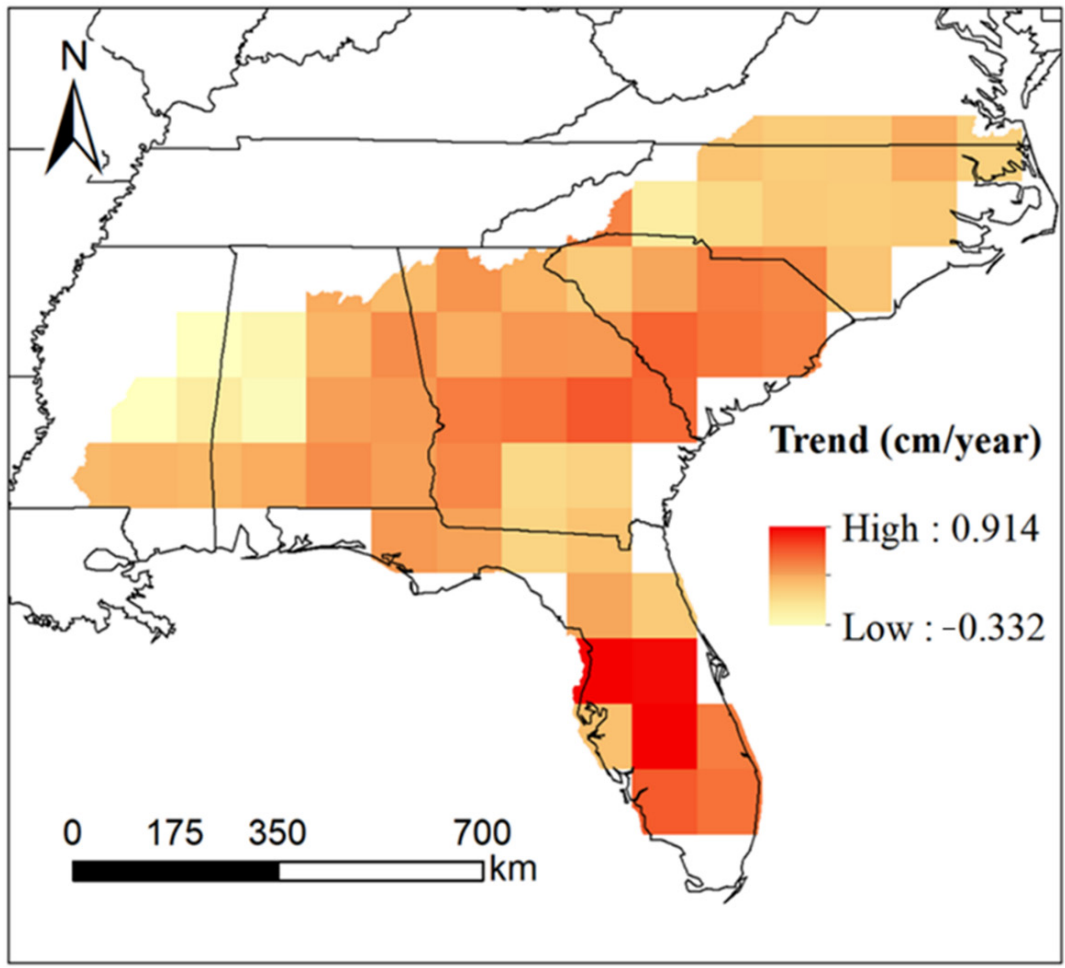

Figure 3. Mean monthly temporal graph of (i) ENSO index and GWSA. (ii) Precipitation and recharge. (iii) Spatial variation of a magnitude of a trend for a period of 2002-2019. On (i), the blue line, the red shaded areas and the blue shaded areas represents GWSA, El Niño and La Niña, respectively. On (ii), the red line and the blue bar represents recharge and precipitation anomaly, respectively. 
The recharging capacity of the aquifer has a key role in groundwater fluctuations. In this study, the LSM used for recharge does not simulate the anthropogenic impacts. From Figure 3ii, it is clear that a strong seasonal cycle is consistent with GWS. Most of the precipitation contributes to recharging where the soil layers are porous. A report by Grubbs [37], stated that March and September have the highest recharge rates in FAS. In West Central Florida and North Florida, the limestone is exposed at the land surface and lies beneath an unconfined aquifer system. It contains low permeable clays in the upper confining unit and groundwater is contained under pressure. The aquifer system in the study region mostly consists of sand and carbonated rocks. The Upper Floridian aquifer has a shallow permeable zone. Thus, the recharging rate can also be a factor contributing to increasing GWS.

Figure 3iii shows spatial variation of trend magnitude which was calculated by using Theil-Sen's Slope in each grid. The positive trend magnitude suggests an increase in GWS whereas the negative trend magnitude suggests a decrease in GWS over the study period. It is evident from the figure that most of the grids in the Florida region have high trend magnitude in GWSA whereas few negative trends were observed in the Alabama and Mississippi area. A maximum positive trend magnitude observed in the study region was found to be $0.914 \mathrm{~cm} /$ year whereas the lowest trend magnitude of $-0.332 \mathrm{~cm} /$ year was observed over the study period. Most of the grids in Florida showed a significant positive trend at a $90 \%$ confidence level. From this, we can confirm that the southern region has experienced increasing GWSA. Increasing groundwater can also be observed throughout the time series in Figure 3i. From this analysis, groundwater trend and magnitude were observed, and it also gave an overall idea of the fluctuation extent over the study period.

Groundwater is a dynamic system that also plays a major role in the agriculture, drinking water supply, and commercial water use sector and it can also pose a significant threat if the rise is very high. Based on the results, most of the grids have an increasing trend and the increased groundwater was featured in media as well as reported by Suwanee River Management District [36]. It reported increased groundwater mainly in the adjacent district of Dixie County. The correlation analysis between groundwater and ENSO showed a strong relationship whilst precipitation also has a main role in the groundwater fluctuations which is discussed in the subsequent section.

\subsection{Correlation Analysis}

The relationship between precipitation and ENSO over the period 2002-2019 is strongly positive throughout the study area in November and December months as shown in Figure 4. The correlation coefficient values were found to be highest and the most consistent than other months. In July, in most of the grids negative correlation values were observed and in January most grids showed lower significant correlation values (i.e., less than 0.3 ). In all other months, both positive and negative correlation values were observed, whereas in October strong negative correlation was observed in the southern part of Florida. The maximum correlation coefficient for that month is analysis is 0.75 and this higher correlation has been found concentrated in Georgia, South Carolina, Virginia, North Carolina, and few parts of Florida for November and December. In May, correlation is positive and concentrated in the mid-Florida region. The spatiotemporal relationship utilizing Spearman Rank Correlation between gridded precipitation data and the Niño 3.4 index suggests a strong association exists between ENSO and precipitation. 


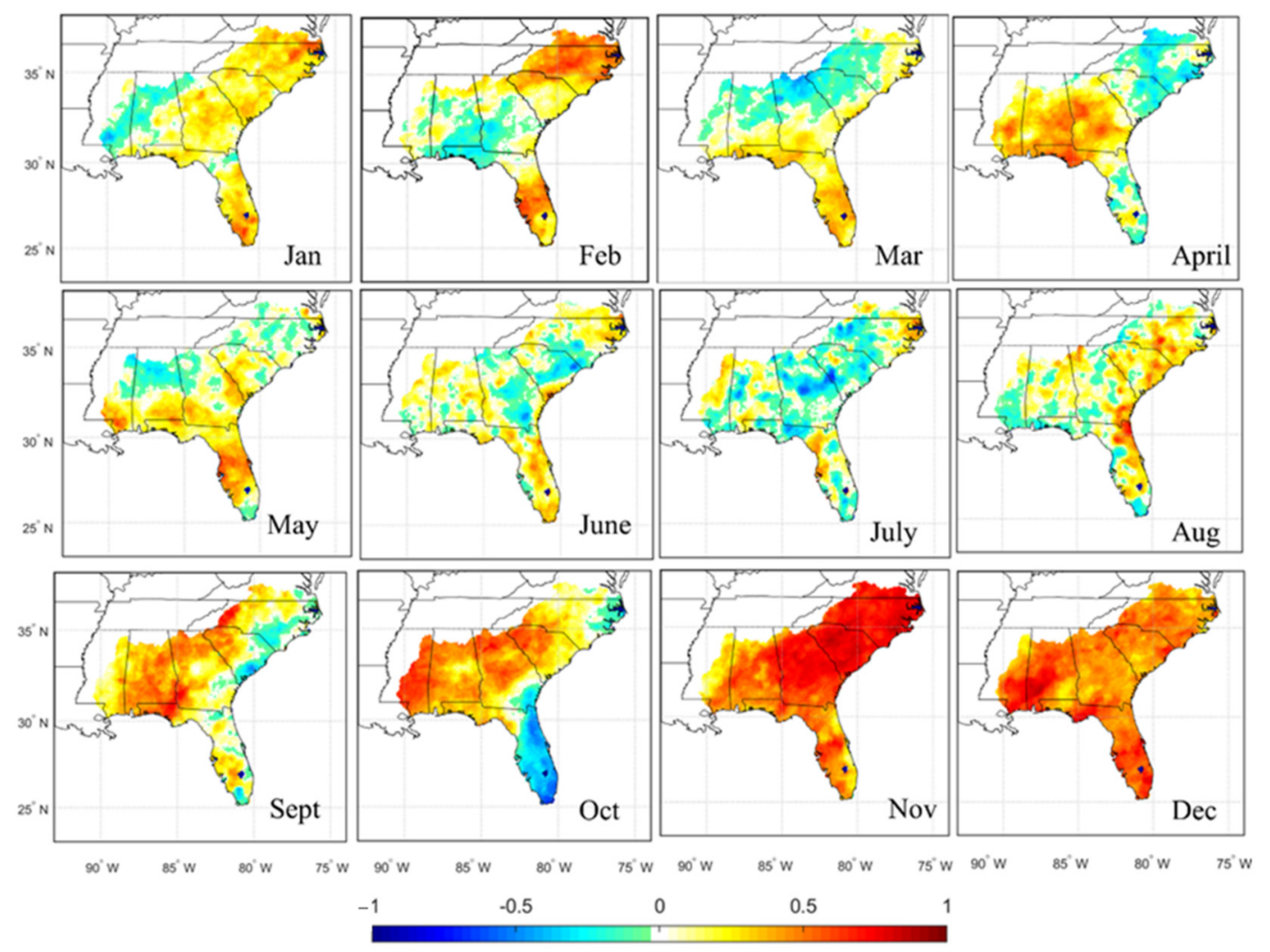

Figure 4. Spatiotemporal correlation maps between precipitation and ENSO.

The climate oscillation is mostly affected by teleconnection signals and ENSO is one of the prominent and important events that lead to anomalies in climate [38]. When sea surface temperature is low and sea level pressure is high then ENSO is considered to occur [39]. This is also supported by several studies in the past [40-42]. ENSO is a tropical pacific pattern and has a strong influence on climate during winter (December-February) across the US. During El Niño jet stream splits into weak polar and strong subtropical jet stream and during La Niña the pacific jet stream are variable [43]. A strong interannual variation was observed from the long-term temporal analysis between precipitation and ENSO (Figure 3ii). A strong interannual variation can be observed as the variabilities in precipitation with high peaks consistent with ENSO events. El Niño events are generally observed in the southern US have wetter and cooler than average condition and in the northern part of the US have the drier condition [44]. High peaks in precipitation were observed during El Niño events followed by La Niña events in the study area. El Niño is related to ocean components and can cause cooling (known as La Niña) or warming (known as El Niño) of SST in the tropical Pacific Ocean. From the results, it can be observed that certain high rainfall events are directly related to ENSO phases. El Niño years have higher rainfall than compared with the La Niña years. It affirms that ENSO plays a significant role in precipitation within the study area. A strong relationship between ENSO and precipitation was observed from the temporal analysis as well as correlation analysis as shown in Figure 3i,ii, respectively. This corresponds with various studies that show precipitation in the Southeast US being predominantly influenced by ENSO phases [34].

The estimated GWSA was used for correlation analysis with the Niño 3.4 index in some areas. Figure 5 represents these results, and it is certain that only in the June, July, and August months, most of the grids of the study region showed a negative correlation coefficient. Most of the grids in June, September and October showed lower correlation coefficient (i.e., less than 0.3). However, a strong correlation coefficient was observed in all other months. The correlation coefficients in this analysis are consistent and positive throughout the study area. Most of the grids in January, February, and March showed a 
strong and positive correlation as shown in Figure 5. The maximum correlation coefficient for these months is 0.91 and this higher correlation has been found concentrated in Mississippi, Alabama, Georgia, South Carolina, North Carolina, and northern parts of Florida. A strong association was also detected between ENSO and precipitation in November and December. This influence also forms a relationship between ENSO and precipitation in the study region, which in turn explains correlations between ENSO and GWSA.

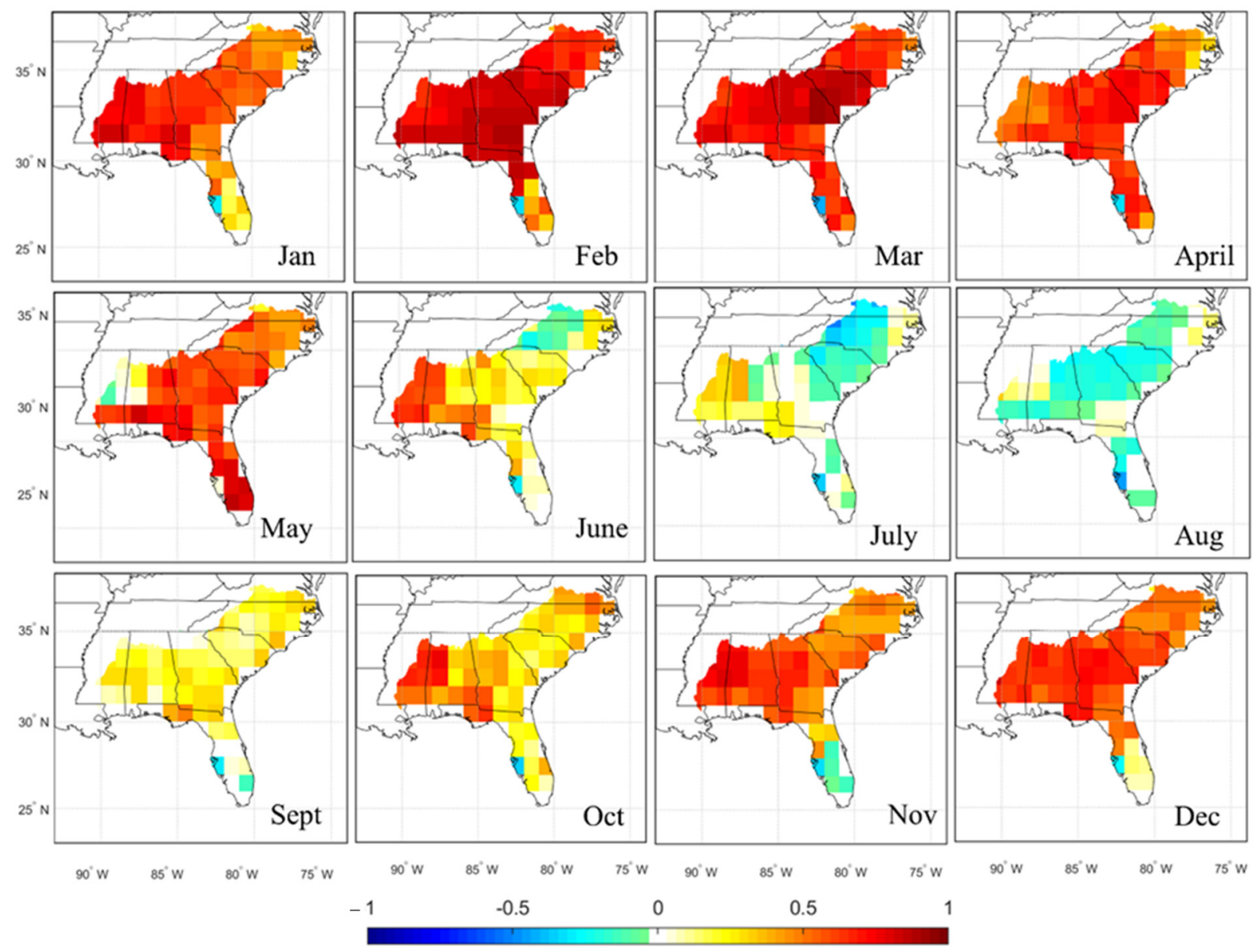

Figure 5. Spatiotemporal correlation maps between GWSA and ENSO.

A similar correlation pattern represents the relationship between ENSO and precipitation across the same region. This trend and the peaking correlation suggest not only that precipitation is the process by which the ENSO is transferred to groundwater, but also that the subsurface plays a role in controlling the magnitude and timing of this ENSO phase. According to NOAA, throughout El Niño event, the eastern winds flowing from the tropical Pacific Ocean are weaker than normal and SST in the eastern and central Pacific become warmer than normal. In the southern part, El Niño events increase wet and cold winters, and in the Northwest, the winter has milder temperatures than normal. During La Niña events, SST in the eastern tropical Pacific is colder than usual. The polar jet stream shifts towards the north throughout the central Pacific Ocean with cold temperatures in the west and wet winters in the northwest. Because of ENSO on precipitation and temperature, it also has a direct or indirect effect on groundwater variability across the Southeast US.

\subsection{Relationship between Groundwater Storage, Precipitation, and Recharge}

Groundwater availability depends on the amount of precipitation, recharge, and production [45]. Precipitation is above normal precipitation during El Niño events in the Southeast US and contrary effects on the Southeast US during La Niña events [46]. A 
wetter than average precipitation in the southeast could therefore be one of the factors influencing the increasing trend in groundwater in the study area. In this study, a strong temporal association between precipitation and groundwater (Figure 3i,ii) also explains and quantifies precipitation-driven groundwater variability, with negative GWSA in La Niña and high groundwater level in El Niño events. Successive precipitation induces increased infiltration leading to increased GWS and recharge. This also indicates that groundwater recharge mostly occurs during El Niño events.

The temporal analysis was used to assess the effects of ENSO on historical GWS variability. It was found that the trend increases from 2007 and it is highly sensitive to El Niño during 2012-2019. During El Niño events, the maximum positive anomaly observed was about $15.9 \mathrm{~cm}$ in February 2019 whereas a minimum of $0.04 \mathrm{~cm}$ in October 2013. Similarly, during La Niña events, the maximum negative anomaly observed was about $-13.4 \mathrm{~cm}$ in October 2007 whereas a minimum of $-0.04 \mathrm{~cm}$ in April 2007. A negative anomaly indicates a deficit of GWS within the study area due to less rainfall or high abstraction, whereas a positive anomaly indicates high recharge due to a high rainfall rate which increases groundwater storage. These increases and decreases in groundwater storage are associated with different ENSO phases and are confirmed by temporal trend plots in Figure 3. The precipitation anomaly analysis indicates that higher GWSA was observed during higher precipitation anomaly whereas lower GWSA during low precipitation anomaly. Furthermore, the net groundwater storage monthly pattern follows the precipitation anomaly data.

The correlation between ENSO and groundwater storage shows that ENSO influences GWSA. The climatic impact of the warm phase, increasing precipitation, seems to appear it increases GWSA. However, there was an apparent delayed response in some major peaks as shown in Figure 3. This may be due to different groundwater responses to climate depending on various factors that affect infiltration and recharge rates such as local geology, land use, and land cover. The study area was covered mostly by the permeable type of rock and the dominant one was sand which could be a potential factor contributing to infiltration leading to increased groundwater storage. Additionally, this study made no distinction between shallow, medium, or deep aquifers. The semiconfined nature of deep aquifers requires the consideration of time attenuation that passes over the unsaturated region and clay layers resulting in long recharge travel time. Climate variables may influence in a different way to shallow and unconfined aquifers at annual timescale, whereas deep confined aquifers at interannual or extended timescale due to soil type, elevation, land use that can take longer time to recharge the aquifer. Hence, in future studies, the distinction of aquifers should also be considered.

The recharge rate was also calculated in the current study. It shows that it has a varying recharge rate over 18 years. It was interesting to note that a recharge of $9.8 \mathrm{~cm}$ was observed in July 2008 over the study period. However, the trend did not increase as that of GWS, but it showed seasonal fluctuation. The average correlation between ENSO and GWSA of the watershed computed by a spatial average was found to be 0.51 . In addition, the correlation values between precipitation and recharge were also computed for the average value of the whole watershed and a very low correlation of 0.32 was obtained. Similarly, the correlation values of GWSA and recharge were also very low (0.001). This may be due existence to the indirect linkage between recharge, precipitation, and groundwater. Moreover, recharge is a slow phenomenon, and it also depends on the land use so it might not have a direct causal relationship with precipitation and groundwater storage. From this, it is clear that increased GWS is not only due to increased recharge. The recharging phenomenon may saturate the portions of the aquifer during the low water periods resulting in increased GWS. The time it takes for the infiltrated water to move from terrestrial area to subsurface may be influenced by other aquifer properties and soil moisture; it can also take months to years as well to respond to precipitation. Extreme precipitation is associated with the recharge rate and may aggravate by soil erosion, high surface runoff, and inundations [47]. Furthermore, Russo and Lall [21] corroborated that climate indices are correlated with GWS changes 
with recharge being strongly influenced by climate such as ENSO. From this analysis, it is evident that the ENSO index has a higher influence on GWS than precipitation and recharge. The recharge and precipitation did not show an increasing trend (Figure 3ii), but it was observed that the strong ENSO events followed by an increased GWSA (Figure 3i) and is also supported by Joshi et al. [26]. Thus, it can be concluded that groundwater aids as an integrator that regulates hydroclimatic and ENSO variability in a particular watershed.

\subsection{Groundwater Rise}

Long-term deviation of GWL is also an essential factor to assess groundwater variability. In this study, normal water level conditions were categorized if groundwater level was found between 25th and 75th percentile, similarly, above normal for GWL higher than 75th percentile and below normal for GWL lower than 25th percentile as shown in Table 1. Out of 247 stations, a maximum of 184 stations showed above normal GWL in February 2016 and 78 showed below normal in May 2007 and is represented in Figure 6. The observed groundwater level variations had a rise in GWL in maximum station however were not uniform every year. A maximum number of stations were observed to be above normal groundwater conditions and is clear from Figure 6. The groundwater wells having less than $10 \%$ missing values were only considered. The sample size was not uniform throughout the study area due to absence of continuous datasets. Therefore, it can also be a potential factor having a maximum number of stations showing above normal groundwater conditions. However, it is clear from the GWSA temporal plot that GWS has an increasing trend. GWSA tends to have a delayed response in few months with precipitation.

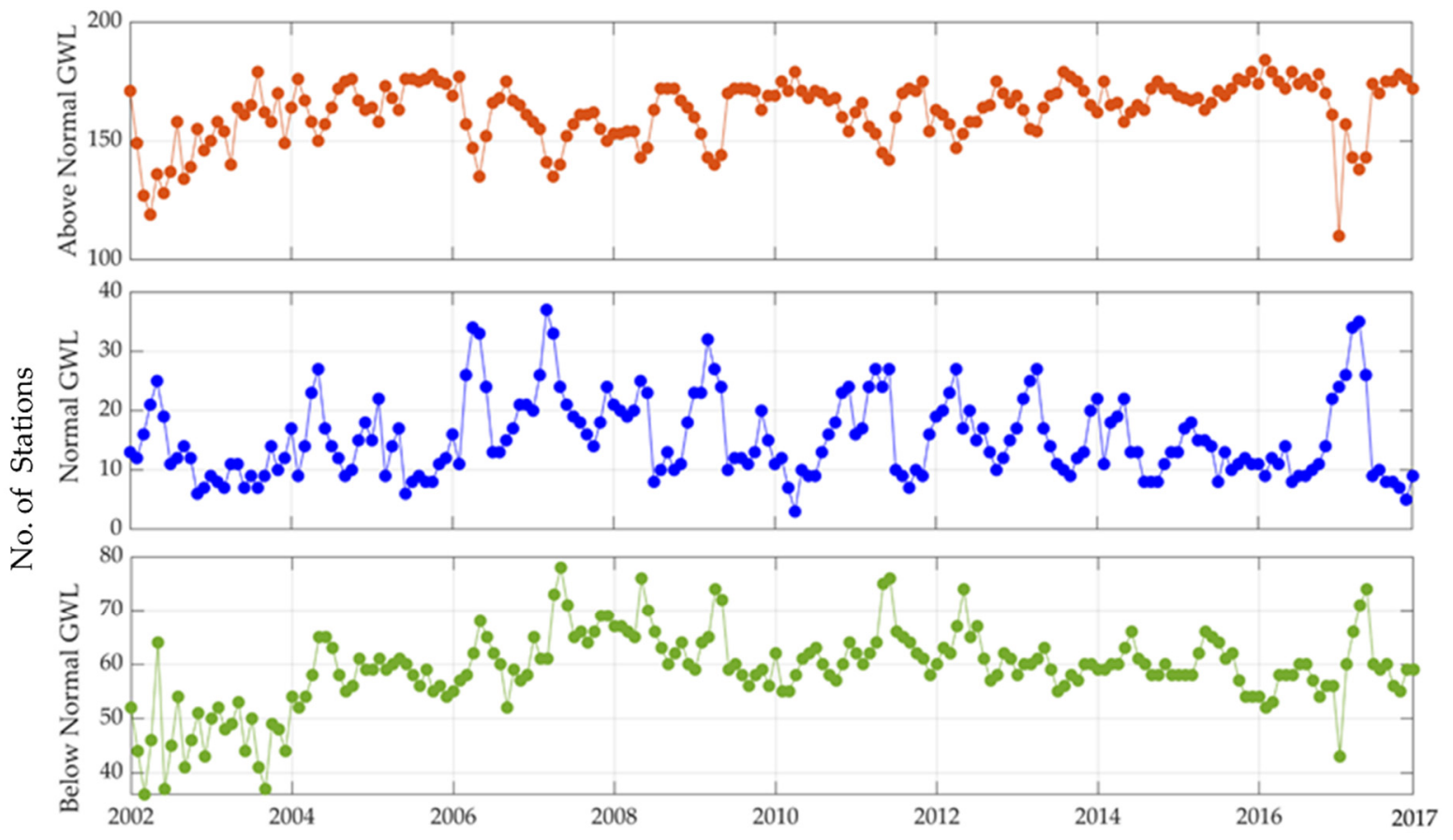

Figure 6. Frequency of stations under three categories: (i) Above Normal in red, (ii) Below Normal in green, and (iii) Normal in the blue line.

The positive precipitation anomaly tends to have a positive groundwater level anomaly, whereas a negative anomaly tends to have a negative groundwater level anomaly. In addition, the wells had a shallow depth to the water table, so it responds quickly to precipitation due to the presence of permeable sand. Sand has high permeability and porosity that increases the rate of recharge. Furthermore, in locations where limestone was a dominant type of rock, 82 wells were found, similarly, in areas having dominant sand layers, 62 wells were found, and 38 wells in clay or mud type were found. 


\section{Conclusions}

In earlier research, groundwater depletion has been a major area of concern, but this study aimed at a less focused research domain, i.e., groundwater rise. The current study intends to analyze the relationship between precipitation, ENSO, and groundwater in the South Atlantic-Gulf Region using robust non-parametric statistical techniques. The GWS changes were investigated by utilizing GRACE and GLDAS gridded datasets over 18 years (2002-2019). The maximum number of GWSA grids was observed to have a strong positive relationship with ENSO within the study period. The frequency of stations exhibiting above normal groundwater level was found to be maximum throughout the study period in comparison to normal and below normal groundwater level.

The main conclusions drawn in this task are as follows:

1. The correlation between ENSO, precipitation, and groundwater was observed to be statistically significant at a 95\% confidence level. February and March had the strongest correlation of 0.91 between GWSA and ENSO whereas and November and December showed a strong correlation of 0.75 between precipitation and ENSO;

2. During high precipitation, the GWS was found to be higher and during less precipitation, GWS was found to be less;

3. During La Niña low precipitation and high precipitation in El Niño were observed. Furthermore, low groundwater storage in La Niña and high groundwater storage in El Niño was found ascertaining the dependence on ENSO climate patterns;

4. A maximum positive groundwater trend magnitude observed was $0.914 \mathrm{~cm} /$ year while the lowest groundwater trend magnitude of $-0.322 \mathrm{~cm} /$ year was observed over the study period;

5. ENSO had a higher influence on GWS fluctuation than precipitation and recharge;

6. Most of the stations were found to be above normal groundwater conditions throughout the study period.

Author Contributions: Conceptualization, A.K.; investigation, N.J.; software, N.J.; formal analysis, N.J.; supervision, A.K.; writing—original draft preparation, N.J. and A.K.; writing—review and editing, N.J. and A.K. All authors have read and agreed to the published version of the manuscript.

Funding: This research received no external funding.

Institutional Review Board Statement: Not applicable.

Informed Consent Statement: Not applicable.

Data Availability Statement: Data available in a publicly accessible repository. The data used in this study are openly available in [GRACE, NOAA, and Groundwater Watch]. The data download links are available in the reference section.

Acknowledgments: The authors would like to thank the editor and four anonymous reviewers for constructive feedback. The authors would like to thank GRACE and USGS for public data access. The authors would like to acknowledge the Dissertation Research Assistantship Award provided by the graduate school at Southern Illinois University, Carbondale.

Conflicts of Interest: The authors declare no conflict of interest.

\section{References}

1. Bates, B.; Kundzewicz, Z.; Wu, S. Climate Change and Water; Intergovernmental Panel on Climate Change Secretariat: Geneva, Switzerland, 2008; p. 210

2. Chen, Z.; Grasby, S.E.; Osadetz, K.G. Relation between climate variability and groundwater levels in the upper carbonate aquifer, southern Manitoba, Canada. J. Hydrol. 2004, 290, 43-62. [CrossRef]

3. Hanson, R.T.; Newhouse, M.W.; Dettinger, M.D. A methodology to asess relations between climatic variability and variations in hydrologic time series in the southwestern United States. J. Hydrol. 2004, 287, 252-269. [CrossRef]

4. Holman, I.P.; Rivas-Casado, M.; Bloomfield, J.P.; Gurdak, J.J. Identifying non-stationary groundwater level response to North Atlantic ocean-atmosphere teleconnection patterns using wavelet coherence. Hydrogeol. J. 2011, 19, 1269-1278. [CrossRef]

5. Figura, S.; Livingstone, D.M.; Hoehn, E.; Kipfer, R. Regime shift in groundwater temperature triggered by the Arctic Oscillation. Geophys. Res. Lett. 2011, 38, 1-5. [CrossRef] 
6. Clark, B.R.; Hart, R.M.; Gurdak, J.J. Groundwater Availability of the Mississippi Embayment; US Geological Survey: Reston, VA, USA, 2011; p. 62.

7. Perez-Valdivia, C.; Sauchyn, D. Tree-ring reconstruction of groundwater levels in Alberta, Canada: Long term hydroclimatic variability. Dendrochronologia 2011, 29, 41-47. [CrossRef]

8. Perez-Valdivia, C.; Sauchyn, D.; Vanstone, J. Groundwater levels and teleconnection patterns in the Canadian Prairies. Water Resour. Res. 2012, 48, 1-13. [CrossRef]

9. Tremblay, L.; Larocque, M.; Anctil, F.; Rivard, C. Teleconnections and interannual variability in Canadian groundwater levels. J. Hydrol. 2011, 410, 178-188. [CrossRef]

10. Treidel, H.; Martin-Bordes, J.L.; Gurdak, J.J. Climate Change Effects on Groundwater Resources: A Global Synthesis of Findings and Recommendations; CRC Press: Boca Raton, FL, USA; Leiden, The Netherlands, 2011.

11. Gurdak, J. Ground-Water Vulnerability: Nonpoint-Source Contamination, Climate Variability and the High Plain Aquifer; VDM: Müller, Germany, 2008.

12. Gurdak, J.J.; Hanson, R.T.; McMahon, P.B.; Bruce, B.W.; McCray, J.E.; Thyne, G.D.; Reedy, R.C. Climate Variability Controls on Unsaturated Water and Chemical Movement, High Plains Aquifer, USA. Vadose Zone J. 2007, 6, 533-547. [CrossRef]

13. Gurdak, J.J.; McMahon, P.B.; Dennehy, K.; Qi, S.L. Water quality in the High Plain aquifer, Colorado, Kansas, Nebraska, New Mexico, Oklahoma, South Dakota, Texas, and Wyoming, 1999-2004. US Geol. Surv. Circ. 2009, 1337, 1-63.

14. McMahon, P.B.; Dennehy, K.F.; Bruce, B.W.; Gurdak, J.J.; Qi, S.L. Water-quality assessment of the High Plains Aquifer, 1999-2004. US Geol. Surv. 2007, 1749, 136.

15. Al-Sefry, S.A.; Şen, Z. Groundwater rise problem and risk evaluation in major cities of arid lands-Jedddah Case in Kingdom of Saudi Arabia. Water Resour. Manag. 2006, 20, 91-108. [CrossRef]

16. Rishma, C.; Katpatal, Y.B. ENSO modulated groundwater variations in a river basin of Central India. Hydrol. Res. 2019, 50, 793-806. [CrossRef]

17. Chinnasamy, P.; Maheshwari, B.; Prathapar, S. Understanding groundwater storage changes and recharge in Rajasthan, India through remote sensing. Water 2015, 7, 5547-5565. [CrossRef]

18. Rahaman, M.M.; Thakur, B.; Kalra, A.; Li, R.; Maheshwari, P. Estimating high-resolution groundwater storage from GRACE: A random forest approach. Environments 2019, 6, 63. [CrossRef]

19. Thomas, B.F.; Famiglietti, J.S. Identifying climate-induced groundwater depletion in GRACE observations. Sci. Rep. 2019, 9, 4124. [CrossRef]

20. Sahoo, S.; Russo, T.; Lall, U. Comment on “Quantifying renewable groundwater stress with GRACE” by Alexandra S. Richey et al. Water Resour. Res. 2016, 52, 4184-4187. [CrossRef]

21. Russo, T.A.; Lall, U. Depletion and response of deep groundwater to climate-induced pumping variability. Nat. Geosci. 2017, 10, 105. [CrossRef]

22. Gravity Recovery and Climate Experiment (GRACE) Mission Release-06 (GRACE-RL06). National Aeronautics and Space Administration: Jet Propulsion Laboratory. California Institute of Technology. Available online: https:/ / podaac-tools.jpl.nasa. gov/drive/files/allData/tellus/L3/mascon/RL06/JPL/v02/CRI/netcdf?fbclid=IwAR3Ws10gTlU4NsV8fo1hBOyuRke7c1 YkLEZLIdsAv_mGlB8vsphpo58tuGo (accessed on 4 July 2020).

23. Wu, Q.; Si, B.; He, H.; Wu, P. Determining regional-scale groundwater recharge with GRACE and GLDAS. Remote Sens. 2019, 11, 154. [CrossRef]

24. Rodell, M.; Houser, P.R.; Jambor, U. The global land data assimilation system. Bull. Am. Meteorol. Soc. 2004, 85, 381-394. [CrossRef]

25. Cao, Y.; Nan, Z.; Cheng, G. GRACE gravity satellite observations of terrestrial water storage changes for drought characterization in the arid land of northwestern China. Remote Sens. 2015, 7, 1021-1047. [CrossRef]

26. Joshi, N.; Kalra, A.; Lamb, K.W. Land-Ocean-Atmosphere Influences on Groundwater Variability in the South Atlantic-Gulf Region. Hydrology 2020, 7, 71. [CrossRef]

27. Li, M.; Hinnov, L.A.; Huang, C.; Ogg, J.G. Sedimentary noise and sea levels linked to land-ocean water exchange and obliquity forcing. Nat. Commun. 2018, 9, 1004. [CrossRef]

28. Download Climate Timeseries Niño 3.4 SST Index. Available online: https://psl.noaa.gov/gcos_wgsp/Timeseries/Data/nino34. long.anom.data (accessed on 5 February 2020).

29. Wilks, D.S. Statistical Methods in the Atmospheric Sciences; Library of Cataloging-in-Publication; Academic Press: San Diego, CA, USA, 1995; p. 465.

30. Thiel, H. A rank-invariant method of linear and polynomial regression analysis, Part 3. In Proceedings of the Koninalijke Nederlandse Akademie van Weinenschatpen A, 30 September 1950; Available online: https://www.dwc.knaw.nl/DL/publications/ PU00018789.pdf (accessed on 11 December 2020).

31. Sen, P.K. Estimates of the regression coefficient based on Kendall's tau. J. Am. Stat. Assoc. 1968, 63, 1379-1389. [CrossRef]

32. Groundwater Watch. Available online: https://groundwaterwatch.usgs.gov/LWLHome.asp (accessed on 9 October 2020).

33. Schmidt, N.; Lipp, E.K.; Rose, J.B.; Luther, M.E. ENSO influences on seasonal rainfall and river discharge in Florida. J. Clim. 2001, 14, 615-628. [CrossRef]

34. Sharda, V.; Srivastava, P.; Ingram, K.; Chelliah, M.; Kalin, L. Quantification of El Niño Southern Oscillation impact on precipitation and streamflows for improved management of water resources in Alabama. J. Soil Water Conserv. 2012, 67, 158-172. [CrossRef] 
35. Hanson, K.; Maul, G.A. Florida precipitation and the Pacific El Nino, 1985-1989. Fla. Sci. FLSCAQ 1991, 54, 404-411.

36. [ARCHIVED] Aquifer Alert System Keeps Residents Informed. Available online: https://www.mysuwanneeriver.com/ CivicAlerts.aspx?AID=650\&ARC $=1302$ (accessed on 21 October 2018).

37. Grubbs, J.W. Recharge Rates to the Upper Floridan Aquifer in the Suwannee River Water Management District, Florida: JW Grubbs; Prepared in Cooperation with the Suwannee River Water Management District; US Department of the Interior, US Geological Survey (USGS): Tallahassee, FL, USA, 1998.

38. Alexander, L.V.; Zhang, X.; Peterson, T.C.; Caesar, J.; Gleason, B.; Klein Tank, A.M.G.; Vazquez-Aguirre, J.L. Global observed changes in daily climate extremes of temperature and precipitation. J. Geophys. Res. Atmos. 2006, 111, 1-22. [CrossRef]

39. Neelin, J.D.; Battisti, D.S.; Hirst, A.C.; Jin, F.F.; Wakata, Y.; Yamagata, T.; Zebiak, S.E. ENSO theory. J. Geophys. Res. Ocean. 1998, 103, 14261-14290. [CrossRef]

40. Joshi, N.; Tamaddun, K.; Parajuli, R.; Kalra, A.; Maheshwari, P.; Mastino, L.; Velotta, M. Future changes in water supply and demand for Las Vegas valley: A system dynamic approach based on CMIP3 and CMIP5 climate projections. Hydrology 2020, 7, 16. [CrossRef]

41. Ruigar, H.; Golian, S. Assessing the correlation between climate signals and monthly mean and extreme precipitation and discharge of Golestan Dam Watershed. Earth Sci. Res. J. 2015, 19, 65-72.

42. Davey, M.K.; Brookshaw, A.; Ineson, S. The probability of the impact of ENSO on precipitation and near-surface temperature. Clim. Risk Manag. 2014, 1, 5-24. [CrossRef]

43. Zhang, P.; Wang, B.; Wu, Z. Weak El Niño and winter climate in the mid-to high latitudes of Eurasia. J. Clim. 2019, 32, 405-421. [CrossRef]

44. U.S. Winter Precipitation During Every El Niño Since 1950. Available online: https:/ / www.climate.gov/news-features/featuredimages/us-winter-precipitation-during-every-el-ni\%C3\%B1o-1950 (accessed on 10 February 2019).

45. Lee, C.H. The determination of safe yield of underground reservoirs of the closed basin type. Trans. ASCE 1915, 78, 148-251.

46. Ropelewski, C.F.; Halpert, M.S. North American precipitation and temperature patterns associated with the El Niño/Southern Oscillation (ENSO). Mon. Weather Rev. 1986, 114, 2352-2362. [CrossRef]

47. Taylor, R.; Tindimugaya, T. The impacts of climate change and rapid development on weathered crystalline rock aquifer systems in the humid tropics of sub-Saharan Africa: Evidence from south-western Uganda. In Climate Change Effects on Groundwater Resources: A Global Synthesis of Findings and Recommendations; Taylor and Francis: Boca Raton, FL, USA, 2011 ; pp. 17-32. 